\title{
The role of amygdala nuclei in the expression of auditory signaled two-way active avoidance in rats
}

\author{
June-Seek Choi, ${ }^{1,3,4}$ Christopher K. Cain, ${ }^{1}$ and Joseph E. LeDoux ${ }^{1,2}$ \\ ${ }^{1}$ Center for Neural Science, New York University, New York, New York 10003, USA; ${ }^{2}$ Nathan Kline Institute for \\ Psychiatric Research, Orangeburg, New York 10962, USA
}

\begin{abstract}
Using a two-way signaled active avoidance (2-AA) learning procedure, where rats were trained in a shuttle box to avoid a footshock signaled by an auditory stimulus, we tested the contributions of the lateral (LA), basal (B), and central (CE) nuclei of the amygdala to the expression of instrumental active avoidance conditioned responses (CRs). Discrete or combined lesions of the LA and B, performed after the rats had reached an asymptotic level of avoidance performance, produced deficits in the $C R$, whereas $C E$ lesions had minimal effect. Fiber-sparing excitotoxic lesions of the LA/B produced by infusions of $N$-methyl-D-aspartate (NMDA) also impaired avoidance performance, confirming that neurons in the LA/B are involved in mediating avoidance CRs. In a final series of experiments, bilateral electrolytic lesions of the CE were performed on a subgroup of animals that failed to acquire the avoidance $C R$ after $3 \mathrm{~d}$ of training. $C E$ lesions led to an immediate rescue of avoidance learning, suggesting that activity in CE was inhibiting the instrumental CR. Taken together, these results indicate that the LA and B are essential for the performance of a 2-AA response. The CE is not required, and may in fact constrain the instrumental avoidance response by mediating the generation of competing Pavlovian responses, such as freezing.
\end{abstract}

Early studies of the neural basis of fear often employed avoidance conditioning procedures where fear was assessed by measuring instrumental responses that reduced exposure to aversive stimuli (e.g., Weiskrantz 1956; Goddard 1964; Sarter and Markowitsch 1985; Gabriel and Sparenborg 1986). Despite much research, studies of avoidance failed to yield a coherent view of the brain mechanisms of fear. In some studies, a region such as the amygdala would be found to be essential and in other studies would not. In contrast, rapid progress in understanding the neural basis of fear and fear learning was made when researchers turned to the use of Pavlovian fear conditioning (Kapp et al. 1984, 1992; LeDoux et al. 1984; Davis 1992; LeDoux 1992; Cain and Ledoux 2008a). It is now well established from such studies that specific nuclei and subnuclei of the amygdala are essential for the acquisition and storage of Pavlovian associative memories about threatening situations (LeDoux 2000; Fanselow and Gale 2003; Maren 2003; Maren and Quirk 2004; Schafe et al. 2005; Davis 2006).

Several factors probably contributed to the fact that Pavlovian conditioning succeeded where avoidance conditioning struggled. First, avoidance conditioning has long been viewed as a two-stage learning process (Mowrer and Lamoreaux 1946; Miller 1948b; McAllister and McAllister 1971; Levis 1989; Cain and LeDoux 2008b). In avoidance learning, the subject initially undergoes Pavlovian conditioning and forms an association between the shock and cues in the apparatus. The shock is an unconditioned stimulus (US) and the cues are conditioned stimuli (CS). Subsequently, the subject learns the instrumental response to avoid the shock. Further, the "fear" aroused by the presence of the CS motivates learning of the instrumental response. Fear reduction associated with successful avoidance has even been proposed to be the event that reinforces avoidance learning

\footnotetext{
${ }^{3}$ Present address: Department of Psychology, Korea University, Anam, Seongbuk, Seoul 136-701, Korea.

${ }^{4}$ Corresponding author.

E-mail j-schoi@korea.ac.kr; fax 82-2-3290-2662.

Article is online at http://www.learnmem.org/cgi/doi/10.1101//m.1676610.
}

(e.g., Miller 1948b; McAllister and McAllister 1971; Cain and LeDoux 2007). Given that Pavlovian conditioning is the initial stage of avoidance conditioning, as well as the source of the "fear" in this paradigm, it would be more constructive to study the brain mechanisms of fear through studies of Pavlovian conditioning rather than through paradigms where Pavlovian and instrumental conditioning are intermixed. Second, avoidance conditioning was studied in a variety of ways, but it was not as well appreciated at the time as it is today; that subtle differences in the way tasks are structured can have dramatic effects on the brain mechanisms required to perform the task. There was also less of an appreciation for the detailed organization of circuits in areas such as the amygdala. Thus, some avoidance studies examined the effects of removal of the entire amygdala or multiple subdivisions (for review, see Sarter and Markowitsch 1985). Finally, fear conditioning studies typically involved a discrete CS, usually a tone, which could be tracked from sensory processing areas of the auditory system to specific amygdala nuclei that process the CS, form the CS-US association, and control the expression of defense responses mediated by specific motor outputs. In contrast, studies of avoidance conditioning often involved diffuse cues, and the instrumental responses used to indirectly measure fear were complex and not easily mapped onto neural circuits.

Despite the lack of progress in understanding the neural basis of avoidance responses, this behavioral paradigm has clinical relevance. For example, avoidance behaviors provide an effective means of dealing with fear in anticipation of a harmful event. When information is successfully used to avoid harm, not only is the harmful event prevented, but also the fear arousal, anxiety, and stress associated with such events; (Solomon and Wynne 1954; Kamin et al. 1963). Because avoidance is such a successful strategy to cope with danger, it is used extensively by patients with fear-related disorders to reduce their exposure to fear- or anxiety-provoking situations. Pathological avoidance is, in fact, a hallmark of anxiety disorders: In avoiding fear and anxiety, patients often fail to perform normal daily activities (Mineka and Zinbarg 2006). 
We are revisiting the circuits of avoidance conditioning from the perspective of having detailed knowledge of the circuit of the first stage of avoidance, Pavlovian conditioning. To most effectively take advantage of Pavlovian conditioning findings, we have designed an avoidance task that uses a tone and a shock. Rats were trained to shuttle back and forth in a runway in order to avoid shock under the direction of a tone. That is, the subjects could avoid a shock if they performed a shuttle response when the tone was on, but received a shock if they stayed in the same place (two-way signaled active avoidance, 2-AA). While the amygdala has been implicated in 2-AA (for review, see Sarter and Markowitsch 1985), the exact amygdala nuclei and their interrelation in a circuit are poorly understood.

We focused on the role of amygdala areas that have been studied extensively in fear conditioning: the lateral (LA), basal (B), and central (CE) nuclei. The LA is widely thought to be the locus of plasticity and storage of the CS-US association, and is an essential part of the fear conditioning circuitry. The basal amygdala, which receives inputs from the LA (Pitkänen 2000), is not normally required for the acquisition and expression of fear conditioning (Amorapanth et al. 2000; Nader et al. 2001), although it may contribute under some circumstances (Goosens and Maren 2001; Anglada-Figueroa and Quirk 2005). The B is also required for the use of the CS in the motivation and reinforcement of responses in other aversive instrumental tasks (Killcross et al. 1997; Amorapanth et al. 2000). The CE, through connections to hypothalamic and brainstem areas (Pitkänen 2000), is required for the expression of Pavlovian fear responses (Kapp et al. 1979, 1992; LeDoux et al. 1988; Hitchcock and Davis 1991) but not for the motivation or reinforcement of aversive instrumental responses (Amorapanth et al. 2000; LeDoux et al. 2009). We thus hypothesized that damage to the LA or B, but not to the CE, would interfere with the performance of signaled active avoidance.

\section{Results}

\section{Electrolytic lesions of the subnuclei}

\section{Acquisition of avoidance conditioned response (CR)}

Of the 117 rats that were initially trained, $87(\sim 74 \%)$ reached the criterion of $80 \%$ correct ( 24 out of 30 trials) or a higher CR rate by the seventh day of training. The average number of training days to reach the criterion was $5.23( \pm 0.42)$. The rats that reached the criterion were randomly assigned to different treatment groups (six groups) for electrolytic lesions of designated amygdala nuclei or to a sham lesion group (SHAM). To demonstrate that the acquisition of avoidance CR was paralleled by the diminution of Pavlovian-type CRs, three response measures obtained from 16 rats that reached the criterion in exactly $5 \mathrm{~d}$ were plotted. Figure 1 shows the acquisition of the avoidance CR, as well as freezing and ultrasonic vocalizations (USVs) during the 15 -sec period prior to the CS. An increase in the avoidance CR rate is evident, as one-way ANOVA shows a statistically significant session effect $\left(F_{(4,75)}=19.22, P<0.01\right)$ (Fig. 1A). The session effect was also statistically significant for the freezing rate $\left(F_{(4,75)}=175.98, P<\right.$ $0.01)$ and for the number of vocalizations $\left(F_{(4,75)}=5.88, P<\right.$ 0.01 ) (Fig. 1B). There was a statistically significant negative correlation between freezing and the avoidance CR $(r=-0.78, P<$ $0.01)$. The data were averaged from a subgroup of 16 rats that reached the avoidance CR rate of $80 \%$ or higher in exactly $5 \mathrm{~d}$.

\section{Histology}

Of the 87 rats that were initially assigned to the six lesion groups, 54 were included in the final analysis after histological
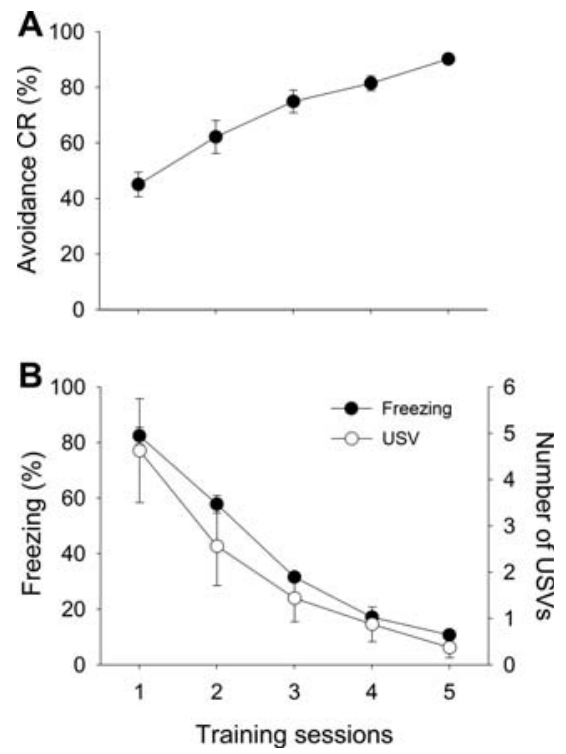

Figure 1. Acquisition of the avoidance response. Data were averaged from animals that had reached the learning criterion on day $5(<80 \%$ avoidance $C R, n=16$ ). (A) Day-to-day changes in avoidance CR rate. $(B)$ Corresponding freezing and ultrasonic vocalizations (USVs) measured from the 15 -sec pre-CS period on every trial.

examination of the lesion sites. Only the animals with substantial damage to the target area and minimal infringement in the surrounding regions were included in the final analysis. Figure 2 shows the reconstruction of the electrolytic lesions.

\section{Behavioral data}

All six groups of animals showed equally high levels of avoidance responses on the last day of acquisition $\left(F_{(5,48)}=0.70, P=0.63\right)$. However, this pattern changed dramatically after the lesionproducing surgery. One-way ANOVA revealed that there was a

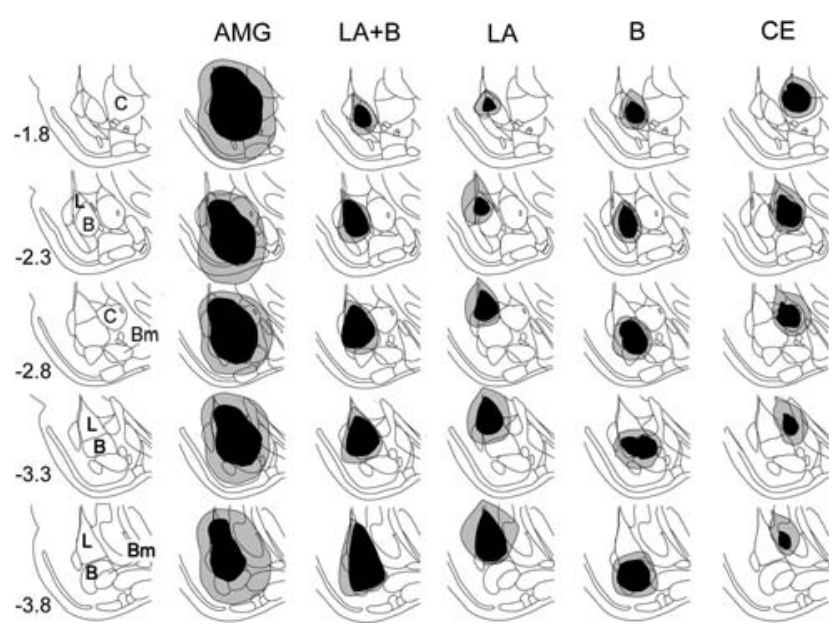

Figure 2. Histological reconstruction of amygdala subnuclei lesions. The black regions indicate the least extensive lesion, and the gray regions indicate the most extensive lesion. In the leftmost column, the numbers indicate the distance in millimeters from the bregma. AMG, entire amygdala; L, LA, lateral nucleus; $B$, basal nucleus; $C, C E$, central nucleus; Bm, basomedial nucleus. Brain images were adapted from Paxinos and Watson (1998) and reprinted here with permission from Elsevier (C) 1998. 
statistically significant difference between lesion groups postsurgery $\left(F_{(5,48)}=20.41, \quad P<0.001\right)$. Planned post-hoc tests (Tukey's) revealed that all lesion groups, except for CE $(P>$ $0.05)$, were significantly different from SHAM $(P<0.05)$ (Fig. 3A). Only the CE group showed avoidance CRs at a level comparable to SHAM during the post-lesion test period. The lesions also had a profound effect on avoidance latency (Fig. 3B). Similar to the CR rate, there was no significant group difference in avoidance latency before the surgery $\left(F_{(5,48)}=0.74, P=0.60\right)$. After the lesion-producing surgery, however, there was a significant group difference $\left(F_{(5,48)}=6.16, P<0.001\right)$. Post-hoc tests (Tukey's) revealed that all lesion groups except for the CE and the entire amygdale (AMG), were significantly different from SHAM. The difference between AMG and SHAM was marginally significant $(P=0.052)$.

\section{Excitotoxic lesions}

\section{Histology}

Intracranial infusions of $N$-methyl-D-aspartic acid (NMDA) destroyed most of the LA and B, with substantial damage in the dorsal endopiriform nucleus and minimal spreading damage in the perirhinal and piriform cortex and capsular division of the CE. The extent of the LA/B lesions from all animals included in the analysis is depicted in Figure 4. Neuronal cell loss was evident from the smaller cell body sizes that occurred as a result
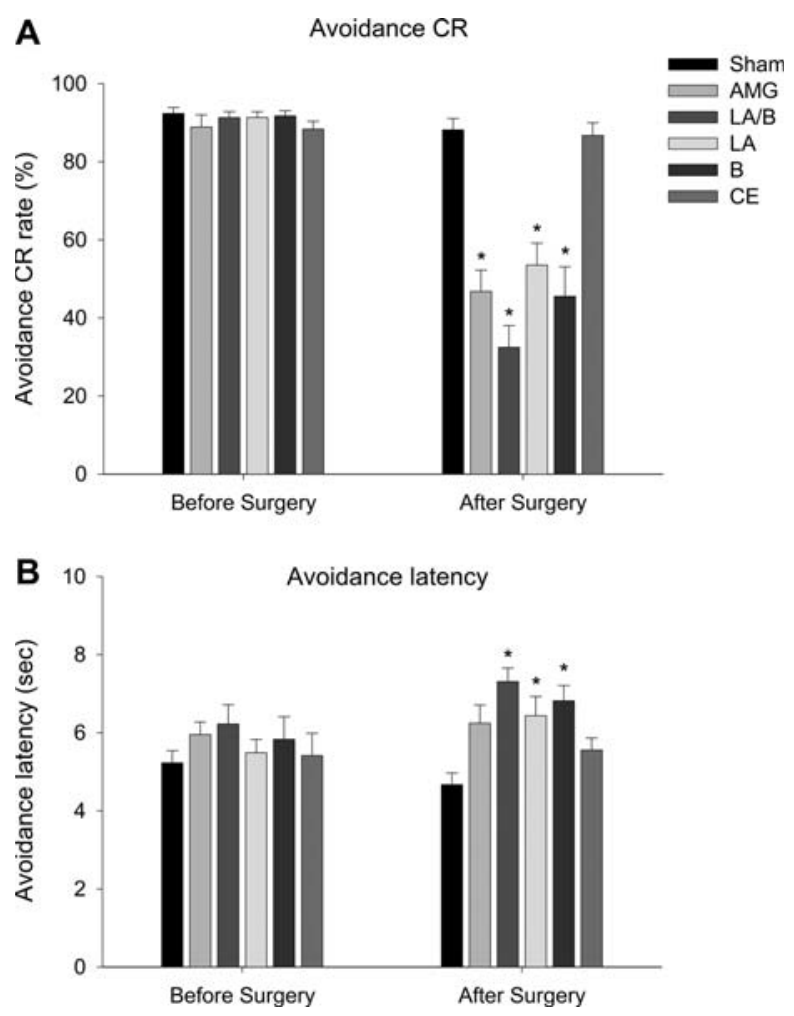

Figure 3. Effects of amygdala subnuclei lesions on avoidance response. (A) Comparison of avoidance CR rates on the last day of training (Before Surgery) and on the first and second day of postsurgical training (Day 1 and Day 2). (B) Comparison of avoidance CR latencies on the last day of training and on the first and second day of postsurgical training. Numbers of subjects included in the analysis were: $\mathrm{SHAM}=10 ; \mathrm{AMG}=$ 9; $\mathrm{LA} / \mathrm{B}=9 ; \mathrm{LA}=9 ; \mathrm{B}=8 ; \mathrm{CE}=9$. An asterisk $\left(^{*}\right)$ indicates statistically significant difference from the SHAM group.

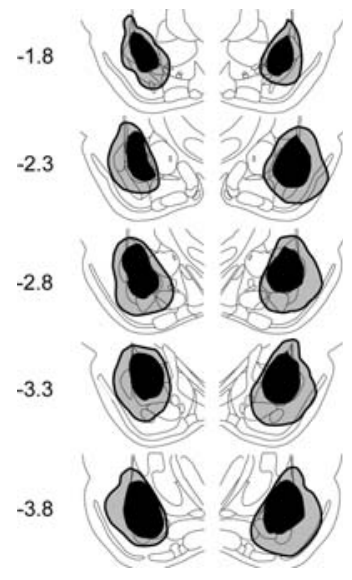

Figure 4. Histological lesion reconstruction for NMDA-lesioned animals. The dark gray areas indicate the lesion size in the least extensive lesioned animal, and the lighter gray areas are from the most extensive lesioned animal. In the leftmost column, numbers indicate the distance in millimeters from the bregma. See Figure 1 for anatomical notations of the amygdala subnuclei. Brain images were adapted from Paxinos and Watson (1998) and reprinted here with permission from Elsevier C 1998.

of cell shrinkage and gliosis. Figure 5 shows representative photomicrographs of a chemical and a sham lesion.

\section{Behavioral data}

Of the 45 rats initially used in the experiment, data were analyzed from 19 animals (10 for the Lesion group and 9 for the SHAM group) after behavioral training and histological verification of the lesion sites. A two-way ANOVA with the session as a withinsubject variable revealed that there was a significant session $\times$ surgical treatment interaction $\left(F_{(1,17)}=16.22, P<0.01\right)$, as well as the main effects of session $\left(F_{(1,17)}=22.91, P<0.01\right)$ and surgical group $\left(F_{(1,17)}=20.67, \quad P<0.01\right)$, indicating that neurotoxic lesions of the LA/B significantly reduced the rate of avoidance $\mathrm{CR}$, compared with the level of presurgical avoidance response. These changes in CR rates were paralleled by the CR latency change. There was a significant session $\times$ surgical treatment interaction $\left(F_{(1,17)}=6.97, P<0.05\right)$, as well as the main effect of session $\left(F_{(1,17)}=5.14, P<0.05\right)$. These results are summarized in Figure 6.

\section{Electrolytic CE lesions in "poor performers"}

Given our results in Figure 1, and our observation that poor avoidance performers showed high freezing, we hypothesized that CE-mediated Pavlovian freezing was interfering with avoidance acquisition. To further examine the role of $\mathrm{CE}$ in the acquisition of avoidance responses, rats with low initial avoidance performance were selected for electrolytic lesions of the CE $(20 \%$ or lower CR rate for the first three sessions of avoidance training). Due to their low rate of avoidance response, these rats received a significant number of shocks ( $25.4 \pm 1.3$ trials/session) throughout the training. The animals did show escape responses, however, by crossing to the nonshock compartment to terminate the shock on a number of trials ( $16.2 \pm 4.5$ trials/session). After $3 \mathrm{~d}$ of training, the poor performers were divided into two groups: $\mathrm{CE}$ Lesion and SHAM. The CE Lesion group received discrete electrolytic lesions of the CE as described above. The SHAM group received the identical surgery, but the electrode was lowered to $1 \mathrm{~mm}$ above the CE and no current was passed. All other training procedures were identical to the experiments described above. 
A

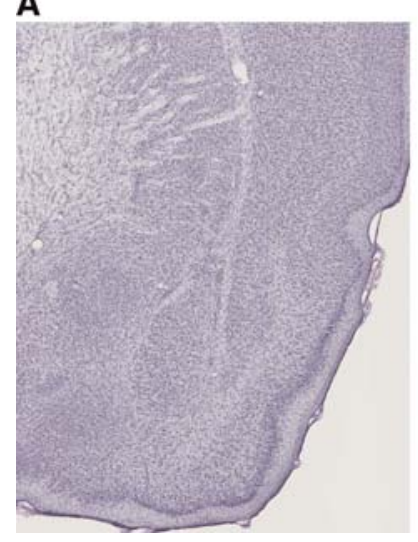

B

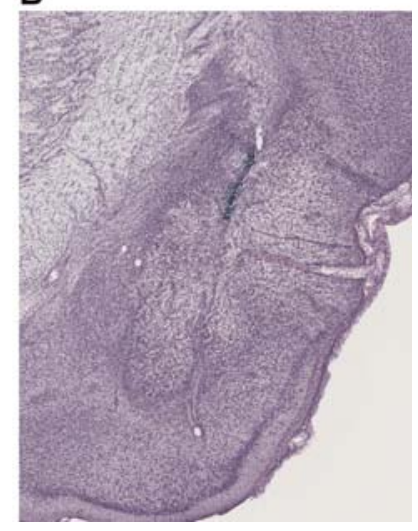

Figure 5. Photomicrographs of representative SHAM and chemical lesions in the LA and B. (A) SHAM-lesion, (B) NMDA lesion.

\section{Histology}

Only the animals with substantial bilateral damage to all subdivisions of the CE were included in the final analysis. The extent of the lesion was similar to that observed in the first series of experiments (Fig. 2, CE lesion reconstruction), and no separate lesion reconstruction is presented here. Although some of the bigger lesions included neurons in the medial border of the B, the LA and B were spared almost completely in most subjects.

\section{Behavioral data}

Of the 18 rats initially used for the CE lesion study, data were analyzed from 13 rats after histological verification (six SHAM and seven CE lesion). ANOVA was conducted on the CR rate using the training day as a within-subject variable, and lesion type as a between-subject variable. There was a significant main effect of both lesion type $\left(F_{(1,11)}=68.61, P<0.01\right)$ and training day $\left(F_{(7,77)}=14.43, P<0.01\right)$. In addition, the interaction of these
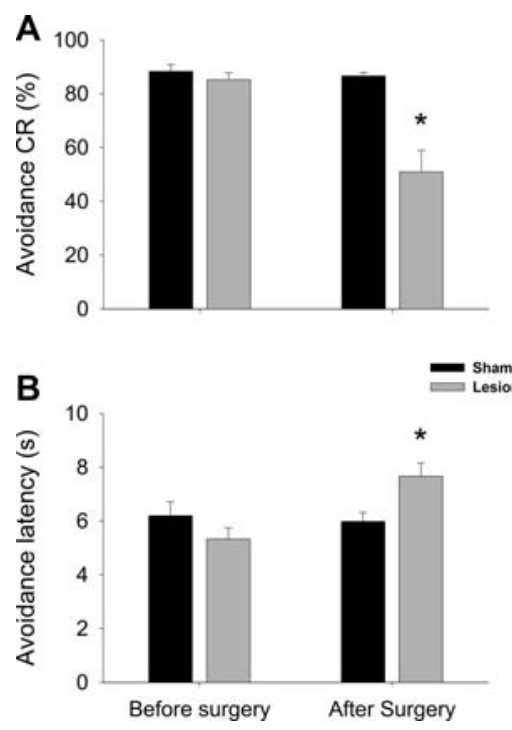

Figure 6. Effect of NMDA lesions on the avoidance response. $(A)$ Comparison of avoidance CR rates. (B) Comparison of avoidance latencies. An asterisk $\left({ }^{*}\right)$ indicates statistically significant difference from the SHAM group. Numbers of subjects included in the analysis were: $\mathrm{SHAM}=9$; Lesion $=9$. variables was significant $\left(F_{(7,77)}=12.22, P<0.01\right)$. To further analyze the source of the interaction, simple main effect tests were performed. There was a significant difference between groups on postsurgical days $1,2,3,4$, and $5\left(F_{(1,7)}>12.19, P<\right.$ $0.01)$, but not on any of the presurgical training days $\left(F_{(1,77)}>\right.$ $0.09, P>0.77$ ) (Fig. 7). These data indicate that the CE-lesioned rats began to show improved performance on the first postsurgical training session and continued to outperform SHAM-lesioned rats throughout the remaining sessions. In addition to the change in avoidance response, CE lesions also altered locomotor activity levels. A repeated-measures ANOVA was performed on baseline intercrossing intervals (ICIs) before and after the surgery. There was a significant group $\times$ session interaction $\left(F_{(1,11)}=6.21, P<\right.$ $0.05)$, indicating that both groups showed equally low levels of locomotor activity, suggestive of freezing, in the shuttle box during the presurgical session, but locomotor activity differed after the surgery. ICIs of the CE Lesion group were significantly shorter than those of the SHAM, even on the first postsurgical session, likely reflecting a reduction of freezing $(22.3 \pm 7.3$ vs. $38.4 \pm 14.9 \mathrm{sec})$.

\section{Discussion}

Given the importance of amygdala nuclei to Pavlovian fear conditioning, and the relationship of Pavlovian fear processes to signaled active avoidance (Mowrer and Lamoreaux 1946; Rescorla and Solomon 1967; Overmier and Lawer 1979), we examined the effect of LA, B, and CE lesions on signaled 2-AA. Other studies have implicated the amygdala in avoidance learning and expression. However, the vast majority of these studies used either lesions of the whole amygdala or combined lesions of two or more amygdala nuclei, often yielding mixed results. For example, although most studies in which the whole amygdala was lesioned in rats have shown impairments in active avoidance (Thatcher and Kimble 1966; Molino 1975; Schutz and Izquierdo 1979; Eclancher and Karli 1980), lesions of the LA and B nuclei together (the basolateral complex) either impaired (Coover et al. 1973a) or facilitated (Campenot 1969) performance. Further, many studies failed to differentiate between avoidance learning and avoidance performance processes. We therefore focused our initial study on amygdala involvement on performance of signaled active avoidance-using animals that were trained to an asymptotic criterion before lesioning. Care was taken to stop training just as the rats reached asymptotic performance, as other studies suggest that training beyond asymptote (overtraining) renders avoidance performance amygdala-independent (Poremba and Gabriel 1999); after extended training, avoidance can become habitual and depend on other regions, possibly the striatum (Yin and Knowlton 2006; LeDoux et al. 2009).

We found that discrete electrolytic lesions of the LA or B, as well as the entire amygdala, severely impaired 2-AA performance signaled by an auditory cue. Rats with LA or B lesions had a lower percentage of successful avoidance responses, and also displayed longer avoidance latencies. For comparison to previous studies, we also included groups with combined lesions of the LA/B or lesions of the entire amygdala. Both of these groups were impaired in post-lesion active avoidance performance. Further, we obtained identical results with excitotoxic NMDA-induced lesions, implicating LA/B cell bodies in active avoidance performance. These results are consistent with several other lines of research. A number of studies have shown impaired active avoidance resulting from permanent lesions (for review, see Goddard 1964; Sarter and Markowitsch 1985) or temporary pharmacological manipulations that target the LA and B together (Poremba and Gabriel 1999). Other studies have shown that training-induced 


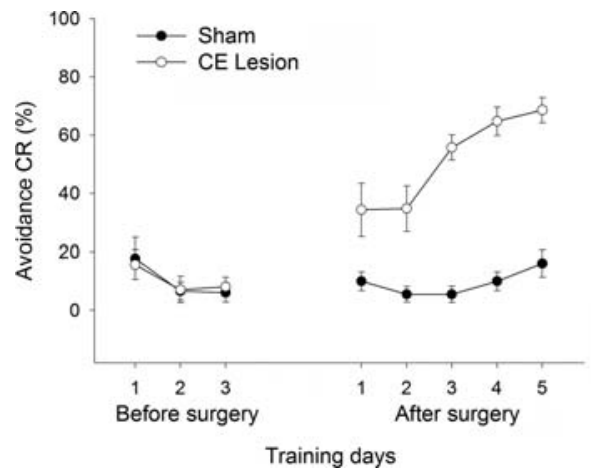

Figure 7. Effect of CE lesions on retarded avoidance learning. Rats with an avoidance CR rate of $20 \%$ or below for 3 consecutive days from the beginning of training were subjected to either a SHAM operation or an electrolytic CE lesion. The graph shows performance in avoidance learning for $3 \mathrm{~d}$ before and $5 \mathrm{~d}$ after the surgery. Numbers of subjects included in the final analysis were: Sham $=6$; CE Lesion $=7$.

neuronal activity changes related to active avoidance acquisition depend on the LA/B, and especially the LA (Poremba and Gabriel 2001). The LA/B complex has also been implicated in other aversive instrumental tasks (Killcross et al. 1997), as well as appetitive instrumental tasks that involve an affectively charged Pavlovian signal (Hatfield et al. 1996). However, to our knowledge, our results are the first to demonstrate impairment of signaled 2-AA performance with discrete and selective lesions of the LA or B alone.

In contrast to the LA and B findings, rats with post-training lesions of CE showed no impairment in 2-AA performance with an auditory cue, which is also consistent with a study that employed the Sidman avoidance paradigm (Lázaro-Muñoz et al. 2009). CE-lesioned rats avoided the shocks as often, and with latencies similar to, the sham-operated rats. This finding supported our hypothesis, which was largely based on the finding that escape from fear (EFF) performance was unimpaired following CE lesions (Amorapanth et al. 2000; see below for further discussion). However, others have reported that CE lesions severely impaired active avoidance (Werka et al. 1978; Sanchez Riolobos 1986; Jain et al. 2000). One study in particular found that CE lesions produced prior to discriminative avoidance training in rabbits greatly slowed avoidance learning (Smith et al. 2001). Several factors may have contributed to this apparent discrepancy. Smith et al. (2001) used pretraining lesions to examine active avoidance acquisition rather than post-training lesions to investigate performance. Thus, the CE may be necessary for an instrumental acquisition process, such as CS-mediated fear reduction important for reinforcement, but not for the CS-mediated motivation to perform avoidance. Alternatively, some theories suggest that cues negatively correlated with shock during training become safety signals that the animals learn to approach (Gray 1975; Ikemoto and Panksepp 1999; Dinsmoor 2001; Brennan et al. 2003). Very little is known about the brain mechanisms of such conditioned inhibition learning, but it remains possible that the CE participates in this process as well. It should also be noted that although the CE was targeted for selective lesions in the Smith et al. (2001) study (and sustained the bulk of the damage), the authors did a thorough job of quantifying damage to surrounding regions, and in each case, there was at least $25 \%$ damage to the LA or B-which may account for the deficit produced. Finally, Smith et al. (2001) used a discriminated avoidance task with CS + and CS - stimulus presentations during training. This may have, for reasons that are not obvious, engaged CE-mediated processes that are not required for our single-signaled avoidance task. Note that our CE findings appear to agree with the electrophysiological data from the same laboratory that training-induced neural activities in extra-amygdala brain regions are intact regardless of the integrity of the CE (for discussion, see Gabriel et al. 2003).

The results from our final series of experiments argue against a necessary role for the CE in signaled 2-AA, and instead suggests that CE-mediated processes can actually prevent the expression of avoidance. In a typical avoidance study, a subset of trained rats fails to learn the avoidance CR ( $<20 \%$ CR rate). Because these rats appeared to show unusually high levels of Pavlovian freezing, we hypothesized that CE lesions may rescue the avoidance deficit, since Pavlovian freezing depends critically on the CE. More specifically, we predicted that CE lesions would enable the poor performers to acquire the task as this would remove the interfering influence of Pavlovian freezing. However, the results were more dramatic than expected, and CE lesions led to a statistically significant improvement in avoidance during the first post-lesion training session, suggesting that these animals had acquired the response but had been impaired in their ability to express this instrumental response due to powerful interfering effects of the CE. The most likely CE-mediated effect that interferes with avoidance is freezing-rats cannot actively avoid if they are frozen. Indeed, we showed above that acquisition of the instrumental avoidance response is correlated with the cessation of freezing. Although CS-elicited freezing was not assessed in this study, CE lesions did significantly reduce pre-CS ICIs compared with SHAM lesions, consistent with disruption of Pavlovian freezing.

One alternative interpretation of these data is that the connections between the $\mathrm{B}$ and the bed nucleus of the stria terminalis (BNST), a component of the extended amygdala, might have been damaged by the indiscriminative electrolytic lesion. The BNST has been implicated in the expression of contextual fear (Sullivan et al. 2004) and in animal models of anxiety (Davis and Shi 1999). It is possible that reduced fear to the context due to damaged projections to the BNST may have alleviated the performance deficit, since a successful 2-AA CR requires overcoming fear of one area. The nature of the competing processes underlying the blockade of instrumental learning in the poor performers and the relative contributions of the CE versus fibers of passage will require further investigation using different lesion and inactivation techniques.

It is also possible that the behavior of the poor-performing rats, because they received greater shock exposure, may resemble learned helplessness (Maier and Seligman 1976), which is also associated with learning deficits. We do not think 2-AA poor performance is related to learned helplessness for several reasons. First, learned helplessness typically involves several hundreds of shocks of very high intensity (up to $1.6 \mathrm{~mA}$ or higher) often combined with restraint. Our poor performers received far fewer shocks of a lower intensity spaced across $3 \mathrm{~d}$, a much less stressful experience. Second, in learned helplessness it is typically the animals that lack any control over the US that demonstrate a subsequent learning deficit. Those that have control show no deficit, in spite of a great deal of shock exposure. In our studies, rats could always escape the shock and did successfully escape the shock on $\sim 50 \%$ of trials. Finally, amygdala lesions that include damage to the CE do not rescue the learning deficit seen with learned helplessness (Maier et al. 1993), whereas 2-AA poor performance was rescued by $\mathrm{CE}$ lesions in our studies.

Our data are consistent with a previous report from our laboratory that implicated the LA and B, but not the CE, in the acquisition and/or performance of another aversively based instrumental response, EFF (Amorapanth et al. 2000). As noted above, one prominent hypothesis regarding avoidance conditioning 
is the two-process theory (Mowrer and Lamoreaux 1946). In this model, subjects first learn a Pavlovian association between the CS and the US on trials where the US is not avoided (early trials). Later in training, the CS participates in motivating and reinforcing avoidance responses. Avoidance responses are said to be reinforced by fear reduction associated with CS termination in trials in which the subject successfully avoids the shock. EFF protocols are very similar to avoidance protocols except that the Pavlovian and instrumental conditioning phases are conducted at separate times and in separate chambers. EFF protocols attempt to isolate CS fear as the important variable in the aversive instrumental learning. During EFF training, subjects are presented with a fear-eliciting CS. Performing the target response leads to the immediate termination of the CS. Note that no shocks are present in EFF sessions. Amorapanth et al. (2000) found that pretraining lesions of the LA or B, but not the CE, impaired the acquisition/performance of EFF, whereas lesions of the LA or $\mathrm{CE}$, but not the $\mathrm{B}$, impaired Pavlovian freezing.

Taken together, our data and earlier EFF results suggest a model in which the LA acquires and stores the Pavlovian fear (CS-US) association, and the CE and B use this association to generate Pavlovian conditioned responses or to motivate active instrumental responses, respectively. Interestingly, it appears that the default response to an aversive CS is the performance of Pavlovian reactions that compete or interfere with instrumental action learning. Most rats respond to the CS with strong CE-mediated Pavlovian fear reactions early in training, but somehow overcome this tendency on their own in the course of avoidance conditioning (see Fig. 1). However, removing the constraining function of the CE through lesions also enables instrumental action in poor performers. Further studies will be needed to pinpoint where in the defensive behavior circuit this critical inhibition of Pavlovian reactions occurs during the normal transition from passive to active responding.

Our findings may appear to contradict learning theories in which fear is assigned a role in avoidance learning and performance, a hypothesis that has been debated for nearly 70 years. However, we adhere to an alternative view of fear that allows for a role in avoidance. Early theories, such as the Miller-Mowrer 2-factor theory, suggested that fear reduction with aversive CS termination reinforces avoidance responses (conditioned negative reinforcement), and, later in training, fear of the CS motivates avoidance responding (Mowrer 1947; Miller 1948a). Other theories, while not invoking a motivational concept of fear, relied on aversive properties of shock-paired cues to explain avoidance (Schoenfeld et al. 1950; Sidman 1953; Dinsmoor 1954). However, these concepts have become quite controversial, mainly because many have reported a lack of parallelism between the magnitude of Pavlovian fear and the strength of avoidance learning (for reviews, see McAllister and McAllister 1971; Mineka 1979) and because of inconsistent learning in EFF paradigms (for discussion, see Cain and LeDoux 2007). Indeed, it is now widely accepted that Pavlovian defensive responses, often used as fear indicators, diminish as avoidance is acquired (Fig. 1; Kamin et al. 1963; Coover et al. 1973b; Starr and Mineka 1977) and return when avoidance responses are prevented (Solomon and Wynne 1954; Lapointe and Baum 1987). Our finding that CE lesions rescue avoidance performance when Pavlovian freezing is high may also suggest a disconnect between Pavlovian fear and instrumental avoidance. This disconnect was, however, a negative correlation, suggesting that Pavlovian responses may constrain avoidance. Much of this debate hinges on the definition of fear and may result from a failure to distinguish between learning and performance (McAllister and McAllister 1991). If one defines fear as the presence of Pavlovian defensive responses, then there appears to be clear evidence from this and other studies that fear and avoidance are unrelated, or inversely related. However, defining fear in terms of Pavlovian responses is somewhat narrow. On the other hand, the broader colloquial meaning of fear commonly used by humans (a subjectively experienced feeling) is probably inappropriate in animal studies (LeDoux et al. 2009). An alternative is to view fear as a central state (Rescorla and Solomon 1967) that can result from exposure to innate or learned stimuli (McAllister and McAllister 1971), making no assumption about Pavlovian defensive responses or conscious feelings. In this view, fear could be indicated in animals by either Pavlovian or instrumental defensive responses. Viewed this way, the current data do not argue against a role for fear in avoidance learning and maintenance.

Avoidance is a hallmark of nearly all forms of pathological anxiety primarily because the avoidance performance tendency is so powerful that it often interferes with normal day-to-day functions. At the same time, avoidance is an extremely effective means of coping with danger. Not only does avoidance performance prevent the delivery of harmful stimuli, but it also inhibits the Pavlovian fear reactions that are associated with the subjective state of fear (Fig. 1; Solomon and Wynne 1954; Cain and LeDoux 2007). Active instrumental coping strategies have also been advocated over passive anxiety treatments because they may be more effective and long lasting (LeDoux and Gorman 2001; van der Kolk 2006). Although researchers largely abandoned avoidance studies in favor of Pavlovian conditioning studies to elucidate the brain mechanisms of fear, it may be time to return to such paradigms using the successful experimental strategies of Pavlovian conditioning studies as a guide. Such work may lead to improved treatments for pathological anxiety and a more comprehensive understanding of brain fear processing.

\section{Materials and Methods}

\section{Subjects}

One hundred sixty-two naïve Sprague-Dawley rats (Hilltop Laboratories) weighing approximately $300 \mathrm{~g}$ at the time of arrival were used for the experiments. Rats were housed individually on a 12-h light/dark cycle (light on at 08:00) and had access to food and water ad libitum. Rats were handled for $5 \mathrm{~min}$ for a minimum of $2 \mathrm{~d}$ before behavioral training began. All procedures were approved by the New York University Animal Care and Use Committee.

\section{Apparatus}

Rats were trained in a shuttle box $\left(25 \times 50 \times 30 \mathrm{~cm}^{3}\right.$; DWH $)$ that was divided into two identical sections by a pair of white opaque Plexiglas dividers. The dividers were $9.5 \times 9.5 \mathrm{~cm}$ protruding from each side of the wall, leaving a narrow passage $(6.5 \mathrm{~cm})$ open between the sections. There was also a hurdle on the bottom of the passage that rose $3 \mathrm{~cm}$ above the grid floor. The grid floor had 32 stainless steel bars arranged in parallel to the dividers (H10-11R-XX-SF, Coulbourn Instruments). Subjects were presented with a $5-\mathrm{kHz}, 70-\mathrm{dB}$ tone $\mathrm{CS}$ that signaled the upcoming footshock US $(0.6 \mathrm{~mA})$, which was delivered by a scrambled shocker (H13-15, Coulbourn instruments). The CS was delivered simultaneously by two speakers located on opposing walls of the chamber $(20 \mathrm{~cm}$ high). The conditioning chamber was placed in a sound-attenuating cubicle (SAC: H10-24A, Coulbourne instruments). The inside of the cubicle was dimly illuminated with two small 0.5-W light bulbs. Animal movement was monitored by an infrared video camera mounted on the ceiling of the SAC. A bat detector (Mini-3, Ultrasound Advice) was placed inside the SAC to monitor ultrasonic vocalization in the range of $22 \mathrm{kHz}$. 


\section{Behavioral training}

Rats were individually trained. For every training session, the animal was placed in the shuttle box and given a minimum 5-min stimulus-free acclimation period to lower the level of contextual freezing. After the acclimation period, rats received 30 signaled avoidance trials with an average intertrial interval (ITI) of $2 \mathrm{~min}$. Trials consisted of a tone CS presentation that lasted a maximum of $15 \mathrm{sec}$. Shuttling during the tone led to immediate tone termination and prevented delivery of the footshock US. If no avoidance shuttle was performed during the 15-sec CS, the US was presented until the rat shuttled (escape response) or for a maximum of $15 \mathrm{sec}$. Training (one session/day) continued for 3 d or until successful avoidance responses were achieved on $>80 \%$ of the trials. However, if an animal did not reach criterion by the seventh session, it was not used in further experiments. If the CR rates remained $<20 \%$ for the first three training sessions, they were removed from the first series of experiments. A subset of these rats was later used in experiments examining CEmediated constraint of avoidance learning/performance (see below). Delivery of stimuli and movement detection were fully automated using a program written with a script language (MedPC, Med Associates Inc.) and required no intervention from an experimenter. Post-lesion sessions were identical to the pre-lesion training sessions.

\section{Behavioral measurement}

The position of the animal was detected by an infrared photobeam source/detector unit, located on the side walls in each section of the shuttle box; $5 \mathrm{~cm}$ above the grid floor and $15 \mathrm{~cm}$ away from the divider. Avoidance latency (the time between the onset of the tone and a break in the photobeam in the other section, if that occurs before the shock onset) or escape latency (in the case of a failed avoidance response; if an escape response is made within the 15 -sec shock limit) was calculated on every trial. To get an estimate of baseline activity, ICIs, the time between crossings from one compartment to another, were also recorded during the acclimation period, before the first CS was presented. Freezing and USVs were scored off-line from the videotape recordings. Freezing was defined as the absence of nonrespiratory movement (Blanchard and Blanchard 1971), and USVs were measured by counting the number of distinct $22-\mathrm{kHz}$ calls (Antoniadis and McDonald 1999; Choi and Brown 2003).

\section{Statistics used}

To analyze the acquisition of avoidance and Pavlovian CRs, one-way ANOVAs were performed on avoidance CR rate, freezing, and ultrasonic vocalizations across multiple training sessions. The analysis was performed using a representative sample of 16 animals. To examine the relationship between the two CR forms (instrumental and Pavlovian), a Pearson correlation coefficient was computed for avoidance CR and freezing rates using data points pooled across 5 training days. To analyze the lesion effect, avoidance CR rates were compared across different lesion groups on the presurgical (last day of training) and postsurgical sessions using ANOVAs. For the chemical lesion experiment, a two-way ANOVA with the session (before and after surgery) as a within-subject variable and surgical group (NMDA lesion or sham lesion) as a between-subject variable was used. For the third series of experiments, a repeated-measures ANOVA was performed on the CR rate of the poor performers across pre- and postsurgical training days. In addition, the baseline ICIs were compared between the lesion and sham control group to detect any significant change in activity level using a repeated-measures ANOVA. All statistical analysis was computed using SPSS (SPSS Inc.) or SAS (SAS Institute Inc.).

\section{Electrolytic lesions}

After the training criterion was reached, rats were divided into six groups, anesthetized with Nembutal $(1.0 \mathrm{~mL} / \mathrm{kg})$ and Atropine $(0.5 \mathrm{~mL} / \mathrm{kg}$ ), and mounted on a stereotaxic frame (David Kopf
Instruments). The skull was exposed and drill holes were made bilaterally. The dura was carefully incised to allow electrode penetration. One group received SHAM lesions (electrode lowered to $1 \mathrm{~mm}$ above the amygdala but no current was applied), and five groups received bilateral electrolytic lesions of the designated structure: entire amygdala (AMG), the LA, the B, combined lesion of LA and B (LA/B), CE or SHAM-operated controls (SHAM). Coordinates were determined based on a previous study from our laboratory (Nader et al. 2001). A stainless steel electrode ( $250 \mu \mathrm{m}$ in diameter), insulated except for the tip was inserted into the target brain area and anodal current was passed to produce a lesion. The size of the tip exposure varied depending on the target site. Table 1 shows the coordinates and other lesion parameters for the different lesion sites. After 7-10 days of recovery, rats were tested using the same parameters as the training session described above.

Rats that were not included in the first experiments were those with low CR rates (poor performers); those whose CR rates were $<20 \%$ for the first $3 \mathrm{~d}$ of training were assigned to SHAM-lesion (SHAM) or CE-lesion surgery groups (CE Lesion). The surgical procedure was identical to that used for the electrolytic central nucleus lesions. After recovery from the surgery, training resumed for 5 additional days.

\section{Chemical lesion}

Fiber-sparing excitotoxic lesions of the LA/B were performed on 45 rats. Rats were anesthetized as described above and mounted on a stereotaxic frame. A pulled glass electrode (1 mm O.D., $0.5 \mathrm{~mm}$ I.D. with a tip diameter of $20-25 \mu \mathrm{m})$ connected to a pressure injector (Picospiritzer III, Parker Hannifin) through clear plastic tubing was loaded using NMDA (Sigma) dissolved in PBS $(20 \mu \mathrm{g} / \mu \mathrm{L})$. Infusions were made at six sites using $0.1 \mu \mathrm{L}$ of the NMDA solution (Lesion) or PBS (SHAM), and the flow of the drug inside the tubing was monitored visually (Koo et al. 2004). The coordinates used for the LA/B lesion were the same as those used in the electrolytic lesion experiments (Table 1). After the surgery, animals were given a minimum of $1 \mathrm{wk}$ to recover before further behavioral testing.

\section{Histology}

Upon completion of the training sessions, rats were deeply anesthetized with chloral hydrate $(400 \mathrm{mg} / \mathrm{kg})$ and perfused transcardially with physiological saline and $10 \%$ buffered formalin.

Table 1. Coordinates and parameters used to produce lesions in the designated area

\begin{tabular}{|c|c|c|c|c|c|}
\hline & Posterior & $\begin{array}{c}\text { Medial/ } \\
\text { lateral }\end{array}$ & Ventral & $\begin{array}{c}\text { Current } \\
\text { duration } \\
\text { (sec) }\end{array}$ & $\begin{array}{c}\text { Tip } \\
\text { exposure } \\
(\mathrm{mm})\end{array}$ \\
\hline $\begin{array}{l}\text { Entire } \\
\text { amygdala }\end{array}$ & 2.3 & $\begin{array}{l} \pm 4.8 \\
+48\end{array}$ & $\begin{array}{l}8.3 \\
8.5\end{array}$ & $\begin{array}{l}20 \\
20\end{array}$ & 0.7 \\
\hline$L A+B$ & 2.3 & $\begin{array}{l} \pm 4.0 \\
\pm 5.0\end{array}$ & $\begin{array}{l}8.5 \\
8 \\
9.1\end{array}$ & $\begin{array}{l}20 \\
10 \\
10\end{array}$ & 0.2 \\
\hline & 3.2 & \pm 5.3 & $\begin{array}{l}8.1 \\
9.2\end{array}$ & $\begin{array}{l}10 \\
10\end{array}$ & \\
\hline & 4 & \pm 5.3 & $\begin{array}{l}8.1 \\
9.3\end{array}$ & $\begin{array}{l}10 \\
10\end{array}$ & \\
\hline LA & $\begin{array}{l}2.3 \\
3.2\end{array}$ & $\begin{array}{l} \pm 5.1 \\
\pm 5.3\end{array}$ & $\begin{array}{l}8 \\
8.1\end{array}$ & $\begin{array}{l}10 \\
10\end{array}$ & 0.2 \\
\hline & 4 & \pm 5.5 & 8.1 & 10 & \\
\hline B & $\begin{array}{l}2.1 \\
2.8 \\
3.3 \\
4.2\end{array}$ & $\begin{array}{r} \pm 4.9 \\
\pm 4.9 \\
\pm 5.3 \\
\pm 5.3\end{array}$ & $\begin{array}{l}9.1 \\
9.3 \\
9.2 \\
9.3\end{array}$ & $\begin{array}{l}12 \\
12 \\
12 \\
12\end{array}$ & 0.2 \\
\hline CE & $\begin{array}{l}1.8 \\
2.3\end{array}$ & $\begin{array}{l} \pm 4.4 \\
\pm 4.4\end{array}$ & $\begin{array}{l}8.2 \\
8.5\end{array}$ & $\begin{array}{l}10 \\
10\end{array}$ & 0.5 \\
\hline
\end{tabular}

Lesions were made by passing DC current of $0.6 \mathrm{~mA}$ through an electrode insulated with epoxy coating except for the tip at the indicated length. The coordinates were modified from a previous study (Nader et al. 2001). 
The brains were removed and soaked in a 30\% sucrose-10\% formalin solution for a minimum of $3 \mathrm{~d}$. The brains were then cut into $50-\mu \mathrm{m}$ sections using a microtome. Sections were stained with cresyl violet, mounted, and examined under a microscope. Camera lucida was used to outline the extent of the lesion.

\section{Acknowledgments}

This work was supported by the National Institute of Mental Health grant, NIMH R32 MH38774 and National Science Foundation Grant ISO 0920153 to J.E.L.; a NRSA F32 MH077458 grant to C.K.C.; and by the National Research Foundation of Korea grant funded by the Korea government (MEST) (No. 2009008145) to J.S.C. We thank Jung-Soo Han for technical advice on NMDA lesions and Junchol Park for useful discussions.

\section{References}

Amorapanth P, LeDoux JE, Nader K. 2000. Different lateral amygdala outputs mediate reactions and actions elicited by a fear-arousing stimulus. Nat Neurosci 3: 74-79.

Anglada-Figueroa D, Quirk GJ. 2005. Lesions of the basal amygdala block expression of conditioned fear but not extinction. J Neurosci 25: 9680-9685

Antoniadis EA, McDonald RJ. 1999. Discriminative fear conditioning to context expressed by multiple measures of fear in the rat. Behav Brain Res 101: 1-13.

Blanchard RJ, Blanchard DC. 1971. Defensive reactions in the albino rat. Learn Motivat 2: 351-362.

Brennan FX, Beck KD, Servatius RJ. 2003. Lever press escape/avoidance conditioning in rats: Safety signal length and avoidance performance. Integr Physiol Behav Sci 38: 36-44.

Cain CK, LeDoux JE. 2007. Escape from fear: A detailed behavioral analysis of two atypical responses reinforced by CS termination. J Exp Psychol Anim Behav Process 33: 451-463.

Cain CK, Ledoux JE. 2008a. Emotional processing and motivation: In search of brain mechanisms. In Handbook of approach and avoidance motivation (ed. AJ Elliot), pp. 17-34. Taylor and Francis, New York.

Cain CK, LeDoux JE. 2008b. Brain mechanisms of Pavlovian and instrumental aversive conditioning. In Handbook of anxiety and fear (ed. DJ Nutt et al.), pp. 103-125. Elsevier Academic Press, Amsterdam, The Netherlands.

Campenot RB. 1969. Effect of amygdaloid lesions upon active avoidance acquisition and anticipatory responding in rats. J Comp Physiol Psychol 69: $492-497$.

Choi JS, Brown TH. 2003. Central amygdala lesions block ultrasonic vocalization and freezing as conditional but not unconditional responses. I Neurosci 23: 8713-8721.

Coover G, Ursin H, Levine S. 1973a. Corticosterone and avoidance in rats with basolateral amygdala lesions. J Comp Physiol Psychol 85: 111-122.

Coover GD, Ursin H, Levine S. 1973b. Plasma-corticosterone levels during active-avoidance learning in rats. J Comp Physiol Psychol 82: 170-174.

Davis M. 1992. The role of the amygdala in conditioned fear. In The amygdala: Neurobiological aspects of emotion, memory, and mental dysfunction (ed. JP Aggleton), pp. 255-306. Wiley-Liss, Inc., New York.

Davis M. 2006. Neural systems involved in fear and anxiety measured with fear-potentiated startle. Am Psychol 61: 741-756.

Davis M, Shi C. 1999. The extended amygdala: Are the central nucleus of the amygdala and the bed nucleus of the stria terminalis differentially involved in fear versus anxiety? Ann N Y Acad Sci 877: 281-291.

Dinsmoor JA. 1954. Punishment. I. The avoidance hypothesis. Psychol Rev 61: $34-46$.

Dinsmoor JA. 2001. Stimuli inevitably generated by behavior that avoids electric shock are inherently reinforcing. J Exp Anal Behav 75: 311-333.

Eclancher F, Karli P. 1980. Effects of infant and adult amygdaloid lesions upon acquisition of two-way active avoidance by the adult rat: Influence of rearing conditions. Physiol Behav 24: 887-893.

Fanselow MS, Gale GD. 2003. The amygdala, fear, and memory. Ann N Y Acad Sci 985: 125-134.

Gabriel M, Sparenborg S. 1986. Anterior thalamic discriminative neuronal responses enhanced during learning in rabbits with subicular and cingulate cortical lesions. Brain Res 384: 195-198.

Gabriel M, Burhans L, Kashef A. 2003. Consideration of a unified model of amygdalar associative functions. Ann N Y Acad Sci 985: 206-217.

Goddard GV. 1964. Functions of the amygdala. Psychol Bull 62: 89-109.

Goosens KA, Maren S. 2001. Contextual and auditory fear conditioning are mediated by the lateral, basal, and central amygdaloid nuclei in rats. Learn Mem 8: 148-155.
Gray JA. 1975. Elements of a two-process theory of learning. Academic Press, New York.

Hatfield T, Han JS, Conley M, Gallagher M, Holland P. 1996. Neurotoxic lesions of basolateral, but not central, amygdala interfere with Pavlovian second-order conditioning and reinforcer devaluation effects. J Neurosci 16: 5256-5265.

Hitchcock JM, Davis M. 1991. Efferent pathway of the amygdala involved in conditioned fear as measured with the fear-potentiated startle paradigm. Behav Neurosci 105: 826-842.

Ikemoto S, Panksepp J. 1999. The role of nucleus accumbens dopamine in motivated behavior: A unifying interpretation with special reference to reward-seeking. Brain Res Brain Res Rev 31: 6-41.

Jain S, Mathur R, Sharma R. 2000. Foetal amygdalar transplantation facilitates recovery of retention deficit in CeA lesioned rats. Indian J Exp Biol 38: 1014-1019.

Kamin LJ, Brimer CJ, Black AH. 1963. Conditioned suppression as a monitor of fear of the CS in the course of avoidance training. J Comp Physiol Psychol 56: 497-501.

Kapp BS, Frysinger RC, Gallagher M, Haselton JR. 1979. Amygdala central nucleus lesions: Effect on heart rate conditioning in the rabbit. Physiol Behav 23: 1109-1117.

Kapp BS, Pascoe JP, Bixler MA. 1984. The amygdala a neuroanatomical systems approach to its contributions to aversive conditioning. In Neuropsychology of memory (ed. N Buttlers, LR Squire), pp. 473-488. Guilford, New York.

Kapp BS, Whalen PJ, Supple WF, Pascoe JP. 1992. Amygdaloid contributions to conditioned arousal and sensory information processing. In The amygdala: Neurobiological aspects of emotion, memory, and mental dysfunction (ed. JP Aggleton), pp. 229-254. Wiley-Liss, New York.

Killcross S, Robbins TW, Everitt BJ. 1997. Different types of fear-conditioned behaviour mediated by separate nuclei within amygdala. Nature 388: 377-380.

Koo JW, Han JS, Kim JJ. 2004. Selective neurotoxic lesions of basolateral and central nuclei of the amygdala produce differential effects on fear conditioning. J Neurosci 24: 7654-7662.

Lapointe A, Baum M. 1987. Description of spontaneous behavior of individual rats undergoing avoidance-response-prevention (flooding). Psychol Rep 61: 879-885.

Lázaro-Muñoz G, LeDoux JE, Cain CK. 2009. Sidman instrumental avoidance initially depends on lateral and basal amygdala and is constrained by central amygdala-mediated Pavlovian processes. Biol Psychiatry (in press). doi: 10.1016/j.biopsych.2009.12.002.

LeDoux JE. 1992. Neural substrates of emotional memory. In Encyclopedia of learning in memory (ed. LR Squire), pp. 483-486. MacMillan, New York.

LeDoux JE. 2000. Emotion circuits in the brain. Annu Rev Neurosci 23: $155-184$.

LeDoux JE, Gorman JM. 2001. A call to action: Overcoming anxiety through active coping. Am J Psychiatry 158: $1953-1955$.

LeDoux JE, Sakaguchi A, Reis DJ. 1984. Subcortical efferent projections of the medial geniculate nucleus mediate emotional responses conditioned to acoustic stimuli. J Neurosci 4: 683-698.

LeDoux JE, Iwata J, Cicchetti P, Reis DJ. 1988. Different projections of the central amygdaloid nucleus mediate autonomic and behavioral correlates of conditioned fear. J Neurosci 8: 2517-2529.

LeDoux JE, Schiller D, Cain CK. 2009. Emotional reaction and action: From threat processing to goal-directed behavior. In The cognitive neurosciences (ed. MS Gazzaniga), pp. 905-924. MIT Press, Cambridge, MA.

Levis DJ. 1989. The case for a return to a two-factor theory of avoidance: The failure of non-fear interpretations. In Contemporary learning theories: Pavlovian conditioning and the status of traditional learning theory (ed. SB Klein, RR Mowrer), pp. 227-277. Lawrence Erlbaum, Hillsdale, NJ.

Maier SF, Seligman MEP. 1976. Learned helplessness: Theory and evidence. I Exp Psychol: Gen 105: 3-46.

Maier SF, Grahn RE, Kalman BA, Sutton LC, Wiertelak EP, Watkins LR. 1993. The role of the amygdala and dorsal raphe nucleus in mediating the behavioral consequences of inescapable shock. Behav Neurosci 107: 377-388.

Maren S. 2003. What the amygdala does and doesn't do in aversive learning. Learn Mem 10: 306-308.

Maren S, Quirk GJ. 2004. Neuronal signalling of fear memory. Nat Rev Neurosci 5: 844-852.

McAllister WR, McAllister DE. 1971. Behavioral measurement of conditioned fear. In Aversive conditioning and learning (ed. FR Brush), pp. 105-179. Academic Press, New York.

McAllister DE, McAllister WR. 1991. Fear theory and aversively motivated behavior: Some controversial issues. In Fear, avoidance, and phobias: A fundamental analysis (ed. MR Denny), pp. 135-163. Erlbaum, Hillsdale, NJ.

Miller NE. 1948a. Studies of fear as an acquirable drive fear as motivation and fear-reduction as reinforcement in the learning of new responses. $J$ Exp Psychol 38: 89-101. 
Miller NE. 1948b. Studies of fear as an acquirable drive: I. Fear as motivation and fear reduction as reinforcement in the learning of new responses. $J$ Exp Psychol 38: 89-101.

Mineka S. 1979. The role of fear in theories of avoidance learning, flooding, and extinction. Psychol Bull 86: 985-1010.

Mineka S, Zinbarg R. 2006. A contemporary learning theory perspective on the etiology of anxiety disorders: It's not what you thought it was. Am Psychol 61: 10-26.

Molino A. 1975. Sparing of function after infant lesions of selected limbic structures in the rat. J Comp Physiol Psychol 89: 868-881.

Mowrer OH. 1947. On the dual nature of learning: A reinterpretation of "conditioning" and "problem solving." Harvard Educ Rev 17: 102-148.

Mowrer OH, Lamoreaux RR. 1946. Fear as an intervening variable in avoidance conditioning. J Comp Psychol 39: 29-50.

Nader K, Majidishad P, Amorapanth P, LeDoux JE. 2001. Damage to the lateral and central, but not other, amygdaloid nuclei prevents the acquisition of auditory fear conditioning. Learn Mem 8: 156-163.

Overmier JB, Lawer JA. 1979. Pavlovian conditioning and the mediation of avoidance behavior. In The psychology of learning and motivation, (ed. G Bower), Vol. 13, pp. 1-55. Academic Press, New York.

Paxinos G, Watson C. 1998. The rat brain. Academic Press, San Diego, CA.

Pitkänen A. 2000. Connectivity of the rat amygdaloid complex. In The amygdala: A functional analysis (ed. JP Aggleton), pp. 31-115. Oxford University Press, Oxford UK.

Poremba A, Gabriel M. 1999. Amygdala neurons mediate acquisition but not maintenance of instrumental avoidance behavior in rabbits. J Neurosci 19: 9635-9641.

Poremba A, Gabriel M. 2001. Amygdalar efferents initiate auditory thalamic discriminative training-induced neuronal activity. J Neurosci 21: $270-278$.

Rescorla RA, Solomon RL. 1967. Two-process learning theory: Relationships between Pavlovian conditioning and instrumental learning. Psychol Rev 74: 151-182.

Sanchez Riolobos A. 1986. Differential effect of chemical lesion and electrocoagulation of the central amygdaloid nucleus on active avoidance responses. Physiol Behav 36: 441-444.

Sarter M, Markowitsch HJ. 1985. Involvement of the amygdala in learning and memory: A critical review, with emphasis on anatomical relations. Behav Neurosci 99: 342-380.
Schafe GE, Doyere V, LeDoux JE. 2005. Tracking the fear engram: The lateral amygdala is an essential locus of fear memory storage. J Neurosci 25: 10010-10014.

Schoenfeld WN, Antonitis JJ, Bersh PJ. 1950. Unconditioned response rate of the white rat in a bar-pressing apparatus. J Comp Physiol Psychol 43: $41-48$.

Schutz RA, Izquierdo I. 1979. Effect of brain lesions on rat shuttle behavior in four different tests. Physiol Behav 23: 97-105.

Sidman M. 1953. Avoidance conditioning with brief shock and no exteroceptive warning signal. Science 118: 157-158.

Smith DM, Monteverde J, Schwartz E, Freeman JH, Gabriel M. 2001. Lesions in the central nucleus of the amygdala: Discriminative avoidance learning, discriminative approach learning, and cingulothalamic training-induced neuronal activity. Neurobiol Learn Mem 76: 403-425.

Solomon RL, Wynne LC. 1954. Traumatic avoidance learning: The principles of anxiety conservation and partial irreversibility. Psychol Rev 61: $353-385$.

Starr MD, Mineka S. 1977. Determinants of fear over the course of avoidance learning. Learn Motivat 8: 332-350.

Sullivan GM, Apergis J, Bush DE, Johnson LR, Hou M, LeDoux JE. 2004. Lesions in the bed nucleus of the stria terminalis disrupt corticosterone and freezing responses elicited by a contextual but not by a specific cue-conditioned fear stimulus. Neuroscience 128: 7-14.

Thatcher RW, Kimble DP. 1966. Effect of amygdaloid lesions on retention of an avoidance response in overtrained and non-overtrained rats. Psychon Sci 6: 9-10.

van der Kolk BA. 2006. Clinical implications of neuroscience research in PTSD. Ann N Y Acad Sci 1071: 277-293.

Weiskrantz L. 1956. Behavioral changes associated with ablation of the amygdaloid complex in monkeys. J Comp Physiol Psychol 49: $381-391$.

Werka T, Skar J, Ursin H. 1978. Exploration and avoidance in rats with lesions in amygdala and piriform cortex. J Comp Physiol Psychol 92: $672-681$.

Yin HH, Knowlton BJ. 2006. The role of the basal ganglia in habit formation. Nat Rev Neurosci 7: 464-476.

Received October 20, 2009; accepted in revised form December 16, 2009. 


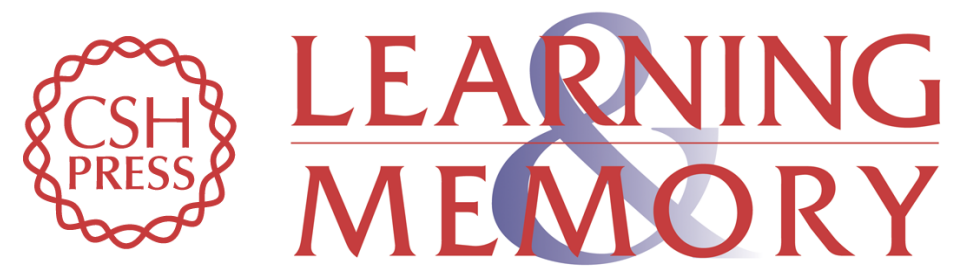

\section{The role of amygdala nuclei in the expression of auditory signaled two-way active avoidance in rats}

June-Seek Choi, Christopher K. Cain and Joseph E. LeDoux

Learn. Mem. 2010, 17:

Access the most recent version at doi:10.1101//m.1676610

References This article cites 64 articles, 13 of which can be accessed free at:

http://learnmem.cshlp.org/content/17/3/139.full.html\#ref-list-1

License

Email Alerting Receive free email alerts when new articles cite this article - sign up in the box at the Service top right corner of the article or click here. 